\title{
INTENSIFICAÇÃO E SOFISTICAÇÃO DOS PROCESSOS DA REGULAÇÃO TRANSNACIONAL EM EDUCAÇÃO: O CASO DO PROGRAMA INTERNACIONAL DE AVALIAÇÃO DE ESTUDANTES*
}

\author{
Luís Miguel Carvalho ${ }^{1}$
}

\begin{abstract}
RESUMO: $\mathrm{O}$ artigo aborda os modos como em um plano transnacional se vêm fabricando agendas para o governo da educação em nome de um conhecimento pericial. Para isso, analisa a intervenção da Organização para a Cooperação e Desenvolvimento Económico (OCDE) por meio de um dos seus principais, senáo o principal, dispositivos - o Programa Internacional de Avaliação de Estudantes (PISA). O artigo faz um balanço nos processos e efeitos das dinâmicas de regulação transnacional no contexto do PISA. Depois, mostra como a intervenção da OCDE no campo educativo se vem intensificando e sofisticando, dando para isso atenção a um conjunto de dinâmicas de alargamento da influência do PISA, por via de novos modos de produçáo, de troca e de difusão de conhecimento pericial.
\end{abstract}

Palavras-chave: OCDE; PISA; regulação transnacional

\section{THE INTENSIFICATION AND SOPHISTICATION OF TRANSNACIONAL GOVERNANCE IN EDUCATION: AN ANALYSIS OF OECD'S PISA}

ABSTRACT: The paper discusses the fabrication of agendas for the education governance in the name of an expert knowledge at a transnational scale. For this, it analyzes the intervention of the Organization for Economic Co-operation and Development (OECD) through one of its main, if not the main, devices - the Programme for International Student Assessment (PISA). The article gives an account of the processes and effects of the dynamics of transnational regulation that occurs with PISA, and shows how the OECD intervention has been intensified and sophisticated, giving attention to a set of dynamics that supports the increasing influence of PISA, via new modes of expertknowledge production, exchange and diffusion.

Keywords: OECD; PISA; transnational governance

\footnotetext{
*O artigo resulta do projeto de pesquisa 'A regulaçáo transnacional das políticas educativas e o trabalho docente' cuja financiadora foi a Cátedra Instituto de Estudos Avançados Transdisciplinares/Santander (UFMG) ${ }^{1}$ Instituto de Educaçáo, Universidade de Lisboa, Portugal. E-mail: Imcarvalho@ie.ulisboa.pt DOI: 10.1590/ES0101-73302016166669
} 


\section{INTENSIFICATION ET SOPHISTICATION DES PROCESSUS DE LA RÉGULATION TRANSNATIONALE EN ÉDUCATION: LE CAS DU PROGRAMME INTERNATIONAL DE L'ÉVALUATION DES ÉLÈVES}

RESUMÉ: L'article adresse la production au niveau transnational des agendas politiques pour le gouvernement de l'éducation au nom de l'expertise. Pour cela, l'article analyse l'intervention de l'OCDE (Organisation de coopération et de développement économique) à travers d'un de ses principaux, sinon le principal, dispositifs d'intervention en éducation - le Programme international de l'évaluation des élèves (PISA). L'article dresse un bilan sur les processus et les effets de la dynamique de régulation transnationale dans le contexte PISA. Ensuite, l'article montre comment l'intervention de l'OCDE dans le domaine de l'éducation a intensifié et sophistiqué, en donnant l'attention sur un ensemble de nouvelles dynamiques d'élargissement de l'influence du PISA grâce à de nouveaux modes de production, d'échange et de diffusion de connaissances spécialisées.

Mots-clés: OCDE; PISA; la réglementation transnationale.

\section{Introdução}

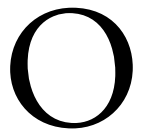

$s$ governos nacionais confrontam-se com o alargamento do campo de ação das organizaçôes internacionais (OIs), cujos questionamentos e preconizações percebem ora como obrigaçóes, ora como recursos indispensáveis para dirigir e administrar os sistemas educativos (BARROSO, 2005). No caso da educação, essas organizações vêm alargando o seu âmbito de ação por meio da difusão de idéias e de normas relativas às estruturas, aos processos e às práticas educativas; mas vêm-no fazendo, ademais, por intermédio da criação de novos espaços e novos instrumentos para o governo da educação (LEUZE; MARTENS; RUSCONI, 2007; RIZVI; LINGARD, 2006). Esse fenómeno não tem apagado o papel dos Estados nacionais nos processos de regulação da educação, mas tem colocado as autoridades nacionais perante novos tipos de desafios e de decisóes, mormente relativas à determinação da localização dos processos de governaçáo e à determinaçáo das agências responsáveis pela coordenação e pelo controlo das açôes no campo educativo (DALE, 1999; LINDBLAD; OZGA; ZAMBETA, 2002). Este artigo apresenta uma análise sobre os modos como as OIs vêm fabricando agendas para o governo da educação em nome de um conhecimento pericial. Concretamente, o artigo versa a intervenção da Organização para a Cooperação e o Desenvolvimento Económico (OCDE) por meio de um dos seus principais, senão o principal, dispositivos de avaliação dos sistemas escolares: o Programa Internacional de Avaliação de Estudantes (PISA) ${ }^{1}$. 
Como é já do conhecimento comum, a OCDE tem um protagonismo assinalável no mundo da educação desde os anos 1960. De tal modo a sua interferência se foi tornando mais e mais significativa, que em muitos Estados começou a ser designada de eminência parda nas políticas educativas (HENRY et al., 2001). Ora, nas duas últimas décadas, a intervençấo da OCDE se vem materializando, mais e mais, por meio de abordagens que vêm tomando como principal forma a "comparação dos Estados, uns com outros, e face a critérios estandardizados" (MARTENS, 2007, p. 40), em vez de focarem, como antes, a situação de cada país per si, respeitando as especificidades nacionais. Essa "viragem comparatista", seguindo os termos de Martens (2007), foi acompanhada pela criação e disseminação de instrumentos que a OCDE apresenta como visando apoiar a monitorização da qualidade e da eficácia dos sistemas educativos. Entre outros dispositivos dessa natureza, sobressai o PISA, preparado no final da década de 1990 e ativado desde o início do presente século (MORGAN, 2007), com regularidade trianual e sem interrupçōes.

Apesar da contestação de que tem siso alvo, por razóes de ordem epistemológica, metodológica, ou mesmo política, o PISA obteve uma consagração expressiva no campo educacional, onde vem servindo para legitimar medidas políticas, instigar pesquisas e animar debates públicos. É possível dizer que se trata de um objeto ao qual políticos, profissionais da comunicação social, investigadores, peritos e altos quadros da administraçáo recorrem com frequência para escrutinar, problematizar ou apontar soluçóes para o setor da educação. Exactamente por isso, o PISA é aqui analisado como um instrumento participante nos processos de regulação, política e social dos sistemas educativos (CARVALHO, 2009). Desse modo, o artigo procura mostrar que a presença do PISA em vários mundos sociais ligados à educação é uma manifestação da relevância atual da "regulação" (DUPRIEZ; MAROY, 2003; BARROSO, 2005) induzida por agências internacionais e exercida com base no conhecimento pericial. Em suma, o artigo aborda o PISA como um analisador da intervenção da OCDE na "regulação transnacional" (BARROSO, 2005; DJELIC; SAHLIN-ANDERSSON, 2006), por meio dessa avaliação internacional comparada, e procura mostrar um dos modos a partir dos quais tal regulação se manifesta: organizando as relaçôes de interdependência entre os variados atores que intervêm nos processos de regulação da educação.

Para desenvolver esse argumento, a primeira parte do texto foca em dois fatores centrais das dinâmicas de regulação transnacional: como opera e que efeitos induz o PISA nos contextos nacionais. Depois, na segunda parte, o texto mostra como se vem intensificando e sofisticando a intervençáo da OCDE na regulação transnacional da educação, dando para isso atenção a um conjunto de novas dinâmicas de alargamento da influência do PISA, por via da criação de novos modos de usar os dados por parte dos seus potenciais utilizadores, mormente pelos decisores políticos nacionais. 


\section{Processos e efeitos da regulação transnacional baseada no conhecimento}

Relativamente ao modo como, no caso do PISA, a regulação transnacional opera, a análise a seguir desenvolvida parte de uma idéia central: a sua influência manifesta-se tanto no plano das idéias, enquadrando problematizaçóes e preconizaçôes sobre os sistemas educativos, quanto no plano da ação organizada, pela configuração das interdependências entre os atores que intervêm nos processos de regulação. Relativamente aos efeitos, a análise concentra-se na clarificação do que pode ser o "efeito de agregaçáa" (LASCOMES; SIMARD, 2011) que o PISA, enquanto instrumento de regulação, gera nos diversos contextos nacionais e culturais que atravessa.

\section{Processos}

A confiança depositada pelos atores nacionais na OCDE, como uma organizaçáo pericial, certamente precede e até promove os julgamentos positivos sobre do PISA como recurso válido e potencialmente útil. Porém essa expectativa tem de ser cumprida em ação: no decurso dos processos de construção e difusão de conhecimento que ocorrem no âmbito do PISA, a OCDE tem de corresponder positivamente à perceção segundo a qual gera um saber especializado, livre de interesses particulares e de circunstâncias particulares e fundado em um relativo consenso científico (NOAKSSON; JACOBSSON, 2003). No âmbito do PISA, a OCDE concretiza essa performance de organização pericial em três planos articulados: na criação de objeto singular e consolidaçáo de um monopólio de conhecimento; na mobilização e coordenação de mundos sociais diversos; na produção e difusão de conhecimento utilizável por mundos sociais diversos.

Relativamente ao primeiro, convém ter presente que o PISA é herdeiro de uma tradição de conhecimento comparado que, desde os anos 1950, vem procurando identificar os fatores explicativos das performances dos sistemas educativos, para encontrar os bons sistemas e as soluçóes associadas à obtençáo dos resultados mais satisfatórios (CARVALHO, 2009; LINDBLAD; PETTERSSON; POPKEWITZ, 2015; MONS, 2007). Porém, o PISA igualmente redirecionou essa tradição, pois desenvolveu um conjunto de características que o diferenciam de antepassados e de concorrentes. Para além de algumas caraterísticas técnicas, importa fixar duas outras novidades (MORGAN, 2007): (1) a garantia dada pela OCDE aos países participantes de integrarem o órgão de direção do programa, envolvendo-os portanto na determinação daquilo que pode ser estudado e escrutinado; (2) a criação de uma área de expertise específica em torno de um objeto singular e novo - a competência de literacia dos estudantes - , afastando-se das soluções postas em marcha anteriormente, prisioneiras dos currículos nacionais. 
Ora, o trabalho de fabricação de um objeto singular resulta do labor intelectual que suporta a conceptualização e a diferenciação desse objeto de avaliação, mas resulta igualmente de um processo de "interessamento" (CALLON, 1986) de pessoas e organizações. Se não há idéias que possam sobreviver sem que existam atores disponíveis para as protagonizar, quem são esses atores? O PISA integra formalmente investigadores e peritos de centros de pesquisa públicos e privados, profissionais da OCDE, decisores políticos e membros da administração da educação, que participam em atividades de inquirição, na elaboraçâao de publicaçóes, em reunióes e em atividades formativas. No que concerne, apenas, aos peritos envolvidos, o PISA depende de peritos em: matérias avaliadas (matemática, leitura, ciências) e suas didáticas, psicometria e psicologia social, além dos peritos associados aos estudos sobre a eficácia das escolas, à econometria e à análise de políticas públicas.

Nesse contexto, o conhecimento gerado no âmbito do PISA é um conhecimento com um carácter "transgressivo" e se "autoriza a si mesmo"” ${ }^{2}$ É transgressivo, relativamente à investigação convencional, porque o seu ponto de partida e o seu ponto de chegada são parcialmente definidos pelos representantes nacionais, náo pelos investigadores ou pelos peritos. Autoriza-se a si próprio, pois a construção dos inquéritos, das análises e das publicaçóes é feita por equipas e por organizaçôes que coletivamente validam a sua própria perícia e que não fazem prova da sua qualidade no contexto das revistas especializadas nem da avaliação pelos pares.

No processo de produção de conhecimento transgressivo e que se autoriza a si mesmo, encontramos uma manifestação da regulação transnacional que se exerce sobre as relaçóes entre conhecimento e política, e entre produtores de conhecimento e políticos: por um lado, as autoridades públicas outorgam o estatuto de experts a certos atores sociais, bem como selecionam e determinam que conhecimento é válido para ser usado no campo político; por outro lado, as autoridades aceitam que esses putativos especialistas sejam parceiros-chave no processo de construção de representaçóes e de regras para coordenação, orientação e controlo do sector educativo; finalmente, as relaçóes entre as autoridades públicas e os peritos nacionais e internacionais são geradas e geridas sob a égide da OCDE, a qual, depois de reunir essa variedade de atores em torno do estudo de um objeto singular, cria condiçóes para que esses interajam regularmente, fixa e arbitra as relaçóes entre esses diferentes mundos, de acordo com valores e regras por si determinadas.

Da mobilização do vasto conjunto de saberes e interesses referidos, gera-se um conhecimento que tem como principais ingredientes as performances dos estudantes e os perfis de competência de literacia de estudantes e países. Ocorre que o conhecimento criado no âmbito do PISA não se circunscreve a tais matérias, pois igualmente oferece análises sobre a variabilidade desses desempenhos em função de relações estabelecidas com fatores de contexto, como estatuto socioeconómico dos estudantes ou a composição social das escolas, e com fatores 
dependentes da decisão política nacional, como o grau de autonomia das escolas ou a estrutura dos currículos. Mais ainda: identifica fatores que devem ser tomados em consideração pelos atores políticos, como questóes políticas cruciais, criando um guião facilitador da análise, da avaliação e da reflexão por parte dos políticos. Ora, essas recomendaçôes versam tópicas que têm sido centrais na agenda da OCDE nas últimas décadas: autonomia das escolas, accountability, privatização, livre escolha da escola, melhoria da escola (MAROY, 2006). Ou seja, o inquérito transforma-se em um lugar de fixação de uma agenda política e de recorrente verificação do seu cumprimento. Assim, a partir dos dados postos à disposição por intermédio do inquérito, emerge uma extensa e relevante "zona de conhecimento cinzento" (POPKEWITZ, 2015), em que se misturam as interpretaçóes dos resultados e a elaboração de recomendaçôes e preconizaçóes para os sistemas educativos nacionais; e que estabelece uma ponte com os decisores políticos e outros profissionais no campo da educação.

Mas para que eles efetivamente usem esse conhecimento, é necessário que o percebam como credível, do ponto de vista científico, mas também como sendo relevante e, sobretudo, manuseável (LINDQUIST, 1990). Por essa razão, no âmbito do PISA se observa a produção de uma variedade de publicaçóes relatórios finais de ciclo, relatórios temáticos, bases de dados, relatórios técnicos, vídeos, manuais metodológicos, etc. - preparadas para serem manuseados por diferentes públicos — políticos, administradores, investigadores, famílias, meios de comunicação social — enfim, passíveis de serem reaproveitadas e desenvolvidas por diferentes utilizadores (CARVALHO; COSTA, 2011). Essa "multiplicação de usos" é, do ponto de vista que sigo, parte indissociável do exercício de uma regulação baseada no conhecimento e orientada para a produção de conhecimento.

Em suma, nos modos de intervenção da OCDE no âmbito do PISA encontram-se os traços fortes de uma regulação transnacional que opera, fundamentalmente, por meio da criação de idéias, da capacidade para conectar mundos sociais diversos na produção, na difusão e no consumo desse conhecimento, garantindo, paralelamente, a imprescindibilidade da agência que o inventou e tem a responsabilidade de geri-lo: a OCDE. Consequentemente, para se conhecer o poder regulatório da OCDE por intermédio do PISA, há de se ter presente os modos como este é acolhido, interpretado e usado nos contextos aos quais é dirigido.

\section{Efeitos}

A expressão "efeito de agregação" (LASCOUMES; SIMARD, 2011) é útil para mostrar que o poder regulador do PISA se concretiza por meio da criação das dependências funcionais e simbólicas que cria; e que tal poder é observável na variedade de usos que desencadeia em contextos habitados por diferentes interesses e por diferentes convicçôes. 
É possível observar esse efeito a partir de uma literatura já consolidada sobre a receção e os efeitos do PISA em contextos europeus (CARVALHO; COSTA, 2011, 2016), da qual emergem três idéias fundamentais:

1. são múltiplos os propósitos que acompanham o uso do PISA;

2. é possível falar de uma presença seletiva do PISA, em função das especificidades dos contextos que o acolhem;

3. apesar da variedade notada nos pontos anteriores, há um traço comum - o PISA é um "ponto de passagem obrigatória" (CALLON, 1986) no escrutínio dos sistemas escolares.

A multiplicidade de propósitos que acompanham a receção e o uso do PISA — dos seus resultados, analises e objetos - nos contextos nacionais pode ser sistematizada em três palavras-chave: legitimação, informaçáo, idealização (CARVALHO; COSTA, 2016). No primeiro caso — legitimação —, observa-se o uso do PISA na validação de reformas educativas (instrumentos de avaliação nacionais) e na promulgação de muitas políticas concretas. Nesse âmbito, é particularmente significativa a variedade de políticas reportadas pela investigação, por toda a Europa, como tendo alguma ligaçáo com a receçâo do PISA. A área curricular é, como esperado, a mais referida e está associada às medidas de alteração de programas e modos de organização dos cursos, ao reforço de currículos centrados em competências e às alteraçóes nos horários escolares. Mas são referidas mudanças em muitas outras áreas: na avaliação dos alunos; em programas de ação prioritária visando os problemas das desigualdades e da segregação; na formação inicial e continuada de professores; na gestáo e avaliação das escolas; e mesmo na restruturaçâo da rede escolar. Por último, mas certamente não por fim, em vários países foram desenvolvidos programas diretamente orientados para melhorar os resultados dos estudantes nacionais nas competências avaliadas pelo PISA. Finalmente, e ainda observando o campo político, uma outra manifestaçáo muito importante é a da inscrição do PISA em metas e em indicadores de desempenho nacionais, sob diversas expressóes: a posição do país no ranking PISA; a pontuação obtida pelo país no PISA; a diminuiçâo de percentagem de alunos com baixos resultados; a alteração de indicadores da variabilidade dos resultados entre escolas (BREAKSPEAR, 2012).

Porém, o PISA é ainda tomado como fonte primária ou suplementar para a pilotagem dos sistemas educativos, ora compensando a falta de dados e informações produzidos nacionalmente, ora acrescentando e/ou confirmando tais conhecimentos, e, finalmente, surge associado à construção de ideários, projeçóes ou narrativas sobre a educação e a reforma da educação (CARVALHO; COSTA, 2016). A essa multiplicidade de usos associam-se processos de seleção de resultados e análises do PISA que decorrem de especificidades políticas e culturais dos contextos que os aco- 
lhem. É já bem conhecido que a presença dos resultados do PISA nos contextos nacionais pode manifestar-se de modos diferentes e com diferentes intensidades: variando entre a glorificação, a escandalização ou a indiferença aos resultados nacionais; ou entre a surpresa, o choque ou a autopromoção (ver, respetivamente, STEINER-KHAMSI, 2003; GREK, 2009). Por outro lado, há evidentes processos de seleção relativamente às grandes áreas sobre as quais a OCDE faz as suas recomendaçóes, sendo algumas consideradas e outras completamente ignoradas ${ }^{3}$. Finalmente, em certos países, o conhecimento efetivamente mobilizado nos debates públicos é muitas vezes reduzido a um número limitado de afirmaçóes simplificadas, enquanto noutros países se verifica a produção intensiva de novos conhecimentos dirigidos aos atores políticos nacionais, combinando ingredientes científicos, técnicos e políticos de modo a explicar ou a ajudar a compreender no âmbito nacional os resultados do PISA, oferecendo, por vezes, traduçôes diferentes e competitivas dos resultados do PISA (ver, e.g., GREK; LAWN; OZGA, 2009; MANGEZ; CATTONAR, 2009; MONS; PONS, 2009; NEUMANN et al., 2012; PONS, 2012).

Esse conjunto de observaçóes sobre a presença do PISA nos contextos nacionais, pela mão de diferentes utilizadores (políticos e outros atores envolvidos nos debates públicos sobre educação, peritos e investigadores nacionais), permite dizer que os materiais providenciados pelo PISA são reinterpretados, tornando-se aceitáveis e eficazes para cada contexto social e cognitivo que os recebe. Tal variedade não é um sinal de fraqueza, mas é o principal sinal da força do PISA como instrumento de regulação, na justa medida em que as divergências verificadas no uso dado ao PISA coexistem com uma convergência para o uso do PISA. É esta manifestação do seu "efeito de agregação": as controvérsias, as ficçōes ou os escrutínios dos sistemas, das políticas e das práticas educacionais são feitas em comprometimento com os seus resultados ou com os seus referenciais. Dito de outro modo, a força do PISA reside na sua compreensão e aceitação como um recurso que é percebido como natural e inevitável para a ação política no sector educativo.

Importa salientar que o discurso recorrente da OCDE não se limita a evidenciar onde estão os bons resultados e os fatores a observar para se retirar liçóes, mas que há países que se preocupam com os resultados e conseguem melhorá-los; ou seja, não se trata de uma intervenção que exerce impacto direto sobre as políticas. De facto, o PISA, como outros meios da regulação transnacional, estabelece o quadro mais geral das possibilidades e das expetativas para as políticas nacionais e estabelece limites para elas, criando uma "meta-política", como referem Dale e Robertson (2014).

\section{Intensificação e sofisticação da regulação transnacional}

Como referem Sellar e Lingard (2014), a OCDE tem procurado aumentar a influência do PISA ao longo do seu ciclo de vida, uma "expansão" envolveu três 
tipos de alteraçóes: a ampliaçáo do espaço geopolítico do inquérito; o alargamento dos objetos e dos sujeitos que sáo avaliados pelo PISA; o alargamento do seu poder explicativo, isto é, a criação de novos modos de usar os dados de modo a alargar a influência do conhecimento proporcionado pelo PISA na decisão política. O texto centra-se, seguidamente, nessa última, de modo a enfatizar a intensificação e a sofisticação dos processos de regulação transnacional. E observa dimensôes da manifestação dessa intensificação e sofisticação: a difusão de conhecimento, atendendo à ampliação da variedade de produtos gerados em audiências muito diversas; a troca de conhecimento, atendendo ao alargamento dos atores que a OCDE póe em interaçáo, a partir do uso dos dados do PISA; a produçáo de conhecimento, atendendo ao aumento dos inquéritos sobre a literacia que vem desenvolvendo. Por razóes de economia do texto, dar-se-á destaque a essa última dimensão.

\section{Sofisticação dos produtos}

Se em 2008, no contexto de uma pesquisa então em curso, foi possível detetar uma significativa variedade de publicaçōes sob a marca PISA — relatórios de vários tipos, bases de dados, documentos metodológicos, cada um deles dirigido a populações-alvo específicas (CARVALHO; COSTA, 2011) —, na atualidade o cenário é diferente: há mais produtos com funções de estímulo à emulação e à aprendizagem política, mormente por meio de uma série de relatórios com estudos de certos países, sugestivamente sob o título "Strong Performers and Successful Reformers". Há novos produtos que oferecem informação de rápido consumo, que em quatro ou cinco páginas dáo respostas práticas sobre temas muito particulares e do interesse de administradores, formadores e professores, tendo por base resultados do PISA (sobre atitudes e desempenhos dos alunos, sobre problemas relacionados com os contextos familiares e até mesmo sobre escolhas políticas). Há novos tipos de produtos que permitem aos utilizadores da plataforma informática criada pela OCDE a construção dos seus próprios modelos de comparações e relatórios tendo por base os dados do PISA.

Essa tecnologia surge associada a uma plataforma sugestivamente designada de "Education GPS". Trata-se de uma plataforma que suporta uma intervenção reguladora de novo tipo na OCDE, por meio da qual, como refere Williamson (2015, p. 12), a OCDE evoluiu de centro de cálculo para centro de visualização de "milóes de observaçóes e medidas" que ali estão "integradas e disponíveis para exame, análise, avaliação e comparação" pelos interessados.

\section{Novos fóruns temáticos}

Uma segunda modalidade da intensificação e da sofisticação dos processos de regulação transnacional, observáveis a partir do PISA, envolve a criação e 
estabilização de novos processos de validação de boas práticas e o estabelecimento de agenda por meio de fóruns temáticos. Uma manifestação particularmente interessante e a merecer mais estudo ocorre desde 2011, no quadro do International Summit on the Teaching Profession (ver ROBERTSON, 2012).

Essa "cimeira" (o termo é, em si, significativo) resulta da cooperação, desencadeada pela OCDE, com a Internacional da Educação (uma federação mundial de associaçôes sindicais e de outras organizaçóes representativas de trabalhadores da educação) e com as autoridades nacionais, especialmente das autoridades dos países onde se realiza. Cada cimeira reúne atores de sistemas educativos (políticos, altos funcionários, sindicalistas e peritos), os quais são selecionados por pertencerem a países que têm melhores performances no PISA ou por serem percebidos como países com melhorias rápidas. As atividades desenvolvidas nas cimeiras baseiam-se em relatórios elaborados propositadamente pela OCDE, mobilizando frequentemente os resultados do PISA e do Teaching and Learning International Survey (TALIS), usados para selecionar e difundir exemplos de "políticas e práticas promissoras" que objetivam melhorar o ensino e o trabalho dos professores ${ }^{4}$.

Trata-se obviamente de um processo de construção de agenda, mas também de criação de um espaço organizado, municiado e arbitrado pela OCDE, para a consensualização entre atores fortes da regulação da educação.

\section{Novas inquirições: uma relação direta com as escolas?}

O alargamento das atividades de inquirição desenvolvidas no âmbito do PISA tem ocorrido pela sua extensão para outras populaçôes-alvo, como os adultos e os estudantes do ensino superior - respetivamente, com o Programme for International Assessment of Adults Competencies (ver, e.g., GREK, 2010) e o Assessment of Higher Education Learning Outcomes - e para outros países, com o PISA for Development (ver ADDEY, 2016). Um outo dispositivo relevante e sobre o qual aqui recai a atenção deste texto é o PISA-based Test for Schools, por meio do qual a OCDE pode vir a ganhar contacto direto com os processos de governo e gestão das escolas, de algum modo flanqueando as autoridades nacionais. Sucintamente, esse novo instrumento integra um conjunto de testes semelhantes aos usados no inquérito PISA. Inclui, portanto, testes escritos e questionários e recorre às mesmas métricas usadas no PISA (de modo a gerar dados comparáveis) 5 . Ocorre que o teste é aplicado nas escolas de modo a produzir conhecimento sobre cada escola participante, sendo, ao final do processo avaliativo, devolvido; já o PISA é aplicado em escolas de um país de modo a avaliar o seu sistema educativo e a produzir conhecimento sobre esse sistema.

As investigaçóes recentes sobre o PISA-based Test for Schools (RUTKOWSKI, 2015; LEWIS; SELLAR; LINGARD, 2016) permitem entender a adesão das escolas, em função de vários fatores: o acesso a dados sobre a sua 
performance e sobre os fatores de contexto e de orientação educativa; o acesso a propostas de boas práticas validadas por uma organização pericial; a possibilidade de introduzir e legitimar mudanças locais em função de evidências e das medidas quantificadas; a possibilidade de partilha de conhecimentos e recursos com outras escolas; a possibilidade de se apresentarem publicamente como instituiçóes orientadas por "padrões" de qualidade mundial e, no caso de terem bons resultados, como fazendo parte de uma elite de escolas de classe mundial e um bem de consumo localmente apetecível.

Esse último fator indicia claramente a presença de uma lógica de certificação externa de qualidade como modalidade para a regulação da oferta e da procura escolar. É, aliás, neste plano — da reflexáo sobre as implicaçóes que uma eventual expansão desse teste possa ter para os processos de regulação da educação (e para a governação das escolas, em particular) — que importa refletir um pouco mais: a emergência e a eventual consolidação desse inquérito configuram uma intensificação dos processos de multirregulação da educação, com um reforço do protagonismo e da influência da regulação transnacional sobre a regulação feita pelas autoridades públicas nacionais.

Em primeiro lugar - e quase óbvio —, o PISA-based Test for Schools permite à OCDE um alargamento do seu espaço de observação e influência sobre as atividades educativas, estabelecendo relaçôes diretas com as escolas e seus dirigentes e gestores, assim podendo fazer chegar as suas injunçôes, com recurso ao conhecimento, diretamente sobre os atores e os processos de governo da escola. É certo que os testes só podem ser realizados com autorização dos governos, mas a intervenção da autoridade nacional esgota-se nessa função.

Em segundo lugar, o programa ativa a presença, nos processos de regulação, de um conjunto significativo de atores não estatais: por um lado, as organizaçôes de filantropia e outras organizaçôes sem fins lucrativos que financiam o programa e as escolas; por outro lado, as organizaçóes multinacionais e nacionais ligadas ao comércio educativo, nomeadamente ligado ao setor dos meios de comunicaçáo social de massa ou das organizaçóes públicas ou privadas da área da investigação e da formação, que são acreditadas pela OCDE para gerir o processo em cada país (o que significa administrar o teste, analisar os dados e produzir relatórios para cada escola, sempre sob supervisão da OCDE). Desse modo, reforça-se o peso da participação nos processos de regulação de atores situados fora da esfera governamental, da administração e, indiretamente, da própria OCDE.

Em terceiro lugar, a inscrição de cada escola em uma rede unida ao redor de dados e de representaçôes educativas veiculadas pela OCDE poderá facilitar a presença, nas escolas, de orientaçóes sobre o seu governo que não estão submetidas aos padróes nacionais e que podem ser argumentadas, legitimadas e até exigidas, em funçáo da sua aproximação a um cânone universal e ao saber técnico-científico. 
Nesse âmbito, pode constituir um importante recurso na disputa pela autonomia das escolas diante da autoridade pública e da regulação vertical. Não deixa, por isso, de ser uma relaçáo construída a partir de uma nova heteronomia — ou seja, de uma nova dependência, já não em relação ao Estado, mas agora diretamente de organizaçóes periciais - que se integra em um fenómeno mais amplo de reforço do papel dos especialistas e das chamadas políticas baseadas nas evidências.

\section{Fecho}

Em toda a configuração de relaçóes descritas ao longo deste texto, a OCDE parece adquirir maior centralidade e capacidade de intermediação, por meio de um modus operandi institucionalizado: idealizando, agregando atores, supervisionando interdependências (ver MARCUSSON, 2004). A partir do PISA, parece claro que há, entre organizaçóes (e entre atores), um espaço no qual sáo trocados recursos materiais, informacionais, financeiros, e mesmo recursos simbólicos, como o status e a reputação dos intervenientes. Trata-se de um espaço no qual, paralelamente, são estabelecidas relaçóes de interdependências entre todas as agências e são colocados em circulação e legitimação modos específicos de entender o que é a educação e como deve ser a escola governada.

E, assim, pede-se regresso ao lugar de início deste texto: a relevância atual de processos de uma regulação transnacional baseada no conhecimento, que opera no campo educacional e atinge relevância nos processos de governo da educação, em dois planos: no plano das idéias, enquadrando problematizações e preconizaçóes sobre os sistemas educativos; mas igualmente no plano da organização das relaçóes de interdependência entre os atores que intervêm nos processos de regulação da educação. O PISA, que ao longo de uma década e meia foi catapultado para a posição de actante significativo nesses processos, parece agora servir de porta de entrada para o alongamento de uma rede de interdependências no setor da educação, senão mesmo ligando-o a outros setores.

\section{Notas}

1. De acordo com Grek (2009), no final da década passada o PISA representava cerca de $30 \%$ do orçamento da sua Diretoria de Educação.

2. Recorre-se a dois dos elementos centrais de uma transfiguração na produção de conhecimento sobre o social, já retratada em literatura dedicada à análise das narrativas dos peritos contemporâneos (NOWOTNY; SCOTT; GIBBONS, 2001).

3. Como mostram Bieber e Martens (2011), o PISA gera orientaçôes e recomendaçôes sobre matérias muito variadas: equidade; padrōes e estruturas escolares nacionais; formação de professores; garantia da qualidade; autonomia da escola; investigação e estatísticas nacionais. 
4. Ver http://istp2015.org/.

5. Teve já aplicaçôes piloto nos Estados Unidos da América, no Reino Unido, no Canadá e na Espanha. A OCDE espera alargar os países envolvidos. Para informaçóes detalhadas, por parte da OCDE, consultar: https://www.oecd.org/pisa/aboutpisa/pisa-based-test-for-schools.htm.

\section{Referências}

ADDEY, C. PISA for development and the sacrifice of policy-relevant data. Educação \& Sociedade, 2016. No prelo.

BARROSO, J. O estado, a educação e a regulação das políticas públicas. Educação \& Sociedade, v. 26, n. 92, p. 725-751, 2005.

BIEBER, T.; MARTENS, K. The OECD PISA study as a soft power in education? Lessons from Switzerland and the US. European Journal of Education, v. 46, n. 1, p. 101-116, 2011.

BREAKSPEAR, S. The policy impact of PISA: an exploration of the normative effects of international benchmarking in school system performance, OECD Education Working Papers, 71. OECD Publishing, 2012.

CALLON, M. Some elements of sociology of translation. In: LAW, J. (Ed.) Power, action, and belief. London: Routledge and Kegan Paul, 1986. p. 196-233.

CARVALHO, L.M. Governando a educação pelo espelho do perito. Educação e Sociedade, v. 30, n. 109, p. 1007-1032, 2009.

CARVALHO, L.M.; COSTA, E. Fabricando o espelho do perito: a construção de conhecimento pericial no mundo PISA. In: L.M. CARVALHO (Coord.). O espelho do perito. V.N. Gaia: Fundação Manuel Leão, 2011. p. 41-76.

CARVALHO, L.M.; COSTA, E. The praise of mutual surveillance in Europe. In: NORMAND, R.; DEROUET, J.-L. (Eds.). A European politics of education. London: Routledge, 2016. p. 53-7.1

DALE, R. Specifying Globalisation Effects on National Policy: a focus on the mechanisms. Journal of Education Policy, v. 14, n. 1, p. 1-17, 1999.

DALE, R.; ROBERTSON, S. Global education policies. In YEATES, N. (Ed.). Understanding global social policy. $2^{\text {nd }}$ ed. Bristol: Policy Press, 2014. p. 209-235.

DJELIC, M.L.; SAHLIN-ANDERSSON, K. Transnational governance. Cambridge: University Press, 2006.

DUPRIEZ, V.; MAROY, C. Regulation in school systems: a theoretical analysis of the structural framework of the school system in French-speaking Belgium. Journal of Education Policy, v. 18, n. 4, p. 375-392, 2003.

GREK, S. Governing by numbers: the PISA “effect” in Europe. Journal of Education Policy, v. 24, n. 1, p. 23-37, 2009.

GREK, S. International Organizations and the shared construction of policy 'problems'. European Educational Research Journal, v. 9, n. 3, p. 396-406, 2010. 
GREK, S.; LAWN, M.; OZGA, J. PISA and the policy debate in Scotland. Sisifo, v. 10, p. 73-84, 2009.

HENRY, M.; LINGARD, B.; RIZVI, F.; TAYLOR, S. The OECD, globalisation and education policy. Oxford: Pergamon Press, 2001.

LASCOUMES, P.; SIMARD, L. L'action publique au prisme de ses instruments. Revue Française de Science Politique, v. 61, n. 1, p. 5-22, 2011.

LEUZE, K.; MARTENS, K.; RUSCONI, A. Introduction. In: MARTENS, K.; RUSCONI, A.; LEUZE, K. (Eds.). New arenas of education governance. London: Palgrave, 2007. p. 3-15.

LEWIS, S.; SELLAR, S.; LINGARD, B. PISA for Schools: topological rationality and new spaces of the OECD's global educational governance. Comparative Education Review, v. 60 , n. 1 , p. $27-57,2016$.

LINDBLAD, S.; OZGA, J.; ZAMBETA, E. Changing forms of educational governance in Europe. European Educational Research Journal, v. 1, n. 4, p. 615-624, 2002.

LINDBLAD, S.; PETTERSSON, D.; POPKEWITZ, T.S. International comparisons of school results: a systematic review of research on large scale assessments in education. Stockholm: Swedish Research Council, 2015.

LINDQUIST, E.A. The third community, policy inquiry, and social scientists. In: BROOKS, S.; GAGNON, A.G. (Eds.). Social scientists, policy, and the State. New York: Praeger, 1990. p. 21-51.

MANGEZ, E.; CATTONAR, B. The status of PISA in the relationship between civil society and the educational sector in French-speaking Belgium. Sisifo, v. 10, p. 15-26, 2009.

MARCUSSON, M. The Organization for Economic Cooperation and Development as ideational artist and arbitrator. In: B. REINALDA; B. VERBEEK (Eds.). Decision making within international organisations. London: Routledge, 2004. p. 90-105.

MAROY, C. Convergências e divergências dos modos de regulação numa perpectiva europeia. In: BARROSO, J. (Coord.). A regulação das políticas públicas de educação: espaços, dinâmicas e actores. Lisboa: Educa, 2006. p. 229-244.

MARTENS, K. How to become an influential actor: The 'comparative turn' in OECD education policy. In: MARTENS, K.; RUSCONI, A.; LEUZE, K. (Eds.). New arenas of education governance. London: Palgrave, 2007. p. 40-56.

MORGAN, C. The OECD Programme for International Student Assessment: unraveling a knowledge network. Tese (Doutorado). School of Public Policy and Administration, Carleton University, Ottawa, 2007.

MONS, N. Lévaluation des politiques éducatives. Apports, limites et nécessaire renouvellement des enquêtes internationales sur les acquis des élèves. Revue internationale de politique comparée, v. 14, n. 3, p. 409-423, 2007.

MONS, N.; PONS, X. The reception of PISA in France: a cognitive approach of institutional debate (2001-2008). Sisifo, v. 10, p. 27-40, 2009. 
NEUMANN, E.; KISS, A.; FEJES, I.; BAJOMI, I.; BERÉNYI, E.; BIRÓ, Z.; VIDA, J. The hard work of interpretation: the national politics of PISA reception in Hungary and Romania. European Educational Research Journal, v. 11, n. 2, p. 227-242, 2012.

NOAKSSON, N.; JACOBSSON, K. The production of ideas and expert knowledge in OECD. Stockholm: Stockholm Centre for Organizational Research, 2003.

NOWOTNY, H.; SCOTT, P.; GIBBONS, R. Re-thinking science: knowledge and the public in the age of uncertainty. Cambridge: Polity Press, 2001.

PONS, X. Going beyond the 'PISA shock' discourse: an analysis of the cognitive reception of PISA in six European countries, 2001-2008. European Educational Research Journal, v. 11, n. 2, p. 206-226, 2012.

POPKEWITZ, T.S. The greyzone: an in-between space of intervention models in Mckinsey and OECD. In: LINDBLAD, S.; PETTERSSON, D.; POPKEWITZ, T.S. International comparisons of school results: a systematic review of research on large scale assessments in education. Stockholm: Swedish Research Council, 2015. p. 130-145.

RIZVI, F; LINGARD, B. Globalisation and the changing nature of the OECD's educational work. In: LAUDER, H.; BROWN, P.; DILLABOUGH, J.A.; HALSEY, A. (Eds.). Education, globalisation and social change. Oxford: Oxford University Press, 2006. p. 129-145.

ROBERTSON, S.L. Placing' teachers in global governance agendas. Comparative Education Review, v. 56, n. 3, p. 584-607, 2012.

RUTKOWSKI, D. The OECD and the local: PISA-based test for Schools in the USA. Discourse: Studies in the Cultural Politics of Education, V. 36, n. 5, p. 683-699, 2015.

SELLAR, B.; LINGARD, B. The OECD and the expansion of PISA. British Educational Research Journal, v. 40, n. 6, p. 917-936, 2014.

STEINER-KHAMSI, G. The politics of league tables. Journal of Social Science Education, v. 1, p. 1-6, 2003.

WILLIAMSON, B. Digital education governance: data visualization, predictive analytics, and 'real-time' policy instruments. Journal of Education Policy, v. 31, n. 2, p. 123-141, 2015.

Recebido em 15 de julho de 2015.

Aprovado em 02 de agosto de 2016. 